\title{
EUTANASIA: CUESTIÓN DE VIDA O MUERTE
}

EUTHANASIA: A QUESTION OF LIFE OR DEATH

La Revista Chilena de Salud Pública se ha esforzado por participar en el debate sobre eutanasia que se reinicia con la publicación de la ya histórica carta del Dr. Manuel Almeyda. Puede parecer demasiado insistente volver sobre el tema en este editorial, pero lo hacemos valorando que, afortunadamente, el afán prematuro de legislar vaya dando paso a una deliberación sostenida de la cual es preciso dar cuenta, vista la relevancia que adquirió en los medios de comunicación.

Mal llamada tema valórico, la eutanasia inquieta a todas las sociedades contemporáneas, debido a diversos factores que le conceden presencia y urgencia: la demografía del envejecimiento de la población, la incidencia creciente de enfermedades crónicas que roen la calidad de vida de los afectados, el expansivo desarrollo de las intervenciones médicas de prolongación de la vida, el cruzamiento entre muerte y disponibilidad de órganos para trasplantes, y la difícil convivencia entre pluralismo y doctrina, todos temas que gatillan debates y disputas entre muerte digna -contraria a la eutanasia-, y dignidad del morir -autonomía por decidir sobre la propia muerte-, solicitando esclarecimiento sobre conceptos, definiciones y criterios de muerte.

Fomentar el debate implica restarse a posturas ideológicas que proponen o se oponen a la eutanasia, que las trincheras pro/contra dificultan el esclarecimiento prejuiciado de lo que finalmente ha de llevar a normativas racionalmente fundadas, tolerantes de la diversidad de doctrinas, dispuestas a fomentar el bien común y las aspiraciones del individuo.

Muy lentamente y con paso inestable, toman posiciones dos convicciones fundamentales pero no fundadas: la eutanasia es indiscutible porque atenta contra valores antropológicos y doctrinarios inamovibles, o la creciente convicción de que el cuerpo humano, la existencia individual, obedece primeramente a sí misma y solo en segunda instancia a significaciones culturales.

Las naciones que han legislado al respecto son pocas, muchas las que enfrentan el requerimiento de entender la necesidad de hablar abiertamente sobre la muerte y, primariamente, sobre la intervención en el proceso de 
muerte. La muerte "por propia mano", el suicidio que hasta no hace mucho se llamaba selbstmord -asesinato de sí mismo-, self-killing, self-slaughter, ha perdido el estigma moral, ha dejado de ser penalizado, aunque continúa maculando la confianza de la sociedad en su compromiso con el bien común. Como decisor y ejecutor son una misma persona, el suicidio se mantiene en el espacio privado, lo que la eutanasia no podría dado el principio de alteridad según el cual la decisión de morir ha de ser ejecutada por otro. La eutanasia no puede sino invadir el espacio público y someterse a legislación que dictamine una regulación rigurosa, sea prohibitiva o permisiva.

El debate se ha enturbiado con la figura del suicidio médicamente asistido, que hace naufragar la distinción esencial entre suicidio y eutanasia, permitiendo que burdos artesanos de la palabra hablen de homicidio en ambos casos, o de un derecho a morir por decisión autónoma, sea por autogestión o solicitada a un tercero. Con grandilocuencia se habla de la dignidad del ser humano, unos señalando que la muerte debe encararse dignamente, otros insistiendo en que la dignidad consiste en elegir la forma y oportunidad de morir.

Esclarecedora es una anotación de Karl Jaspers, exonerado por el nazismo alemán de su cargo de profesor de psicología y filosofía en la Universidad de Heidelberg, exiliado a Suiza por negarse a repudiar a su esposa judía. El texto estaba en su velador, al lado del veneno para él y su mujer: "Declaro para ambos, que no deseamos maniobras de salvataje, más bien solicitamos medidas de eutanasia en caso que la muerte no haya ocurrido con prontitud". El suicidio no fue intentado, y Jaspers, siendo originalmente psiquiatra, tuvo la entereza de abogar -en la Alemania republicana de posguerra-, por el uso de sobredosis letal de medicamentos en pacientes atormentados por los dolores del cáncer avanzado.

Como lo ha hecho con anterioridad, la Revista Chilena de Salud Pública, reitera que hace suya la participación y promoción del debate ciudadano, la reflexión, urgente pero pausada, antes de que nos precipitemos en una legislación atolondrada. Valgan estas líneas como invitación a escribir sobre eutanasia con miras a estimular la deliberación académica sobre el tema. 